\title{
Pseudo-Lignin Formation during Dilute acid Pretreatment for Cellulosic Ethanol
}

\author{
Xianzhi Meng ${ }^{1}$ and Arthur J. Ragauskas ${ }^{1,2,3,4 *}$ \\ ${ }^{1}$ Department of Chemical and Bimolecular Engineering, University of Tennessee -knoxville, USA \\ ${ }^{2}$ Biosciences Division, BioEnergy Science Center, Oak Ridge National Laboratory, USA \\ ${ }^{3}$ UT-ORNL Joint Institute for Biological Science, Oak Ridge National Laboratory, USA \\ ${ }^{4}$ Department of Forestry, Wildlife, and Fisheries, Center for Renewable Carbon, University of Tennessee Institute of Agriculture, USA
}

Submission: March 30, 2017; Published: April 17, 2017

*Corresponding author: Ragauskas AJ, Professor, Department of Chemical and Bimolecular Engineering, USA, Tel: 865-974-2042; Fax: 865-9747076; Email: aragausk@utk.edu

Abstract

Dilute acid-based pretreatment represents one of the most important pretreatment technologies to reduce biomass recalcitrance and it has been successfully applied to a wide range of feedstocks. During this type of pretreatment, the relative lignin content usually increases partially due to the loss of carbohydrates. More importantly, it has been reported that the increase of lignin content after dilute acid pretreatment is mainly due to the formation of pseudo-lignin. The exact reaction mechanisms leading to the formation of pseudo-lignin is still under investigation. However, it has been proposed that rearrangement of hydroxymethylfurfural (HMF) or furfural can produce aromatic type of compounds which can further undergo polymerization reactions to from a lignin-like polyphenolic structures termed as pseudo-lignin. This mini-review mainly covers recent advances in understanding the fundamentals of pseudo-lignin formation during dilute acid pretreatment, the impact of its formation on enzymatic hydrolysis, and how to suppress its formation during dilute acid pretreatment.

Keywords: Biomass recalcitrance; Pseudo-lignin; Dilute acid pretreatment; Enzymatic hydrolysis; Hydroxymethylfurfural; Furfural

Abbreviations: MW: MolecularWeight; Mw: Weight-average molecular weight; Mn: Number-average molecular weight; BT0: 1,2,4-benzenetriol; DMSO: Dimethyl Sulfoxide; HMF: Hydroxymethylfurfural

\section{Introduction}

Increasing global energy demand and environment concerns have led to rapid development of converting renewable resources such as lignocelluloses biomass to biofuels such as cellulosic ethanol [1]. Relatively high costs associated with the bioprocess and the sub-optimal yield of ethanol production remains a great challenge due to the natural resistance of the plant cell wall to enzymatic deconstruction. As a result, a chemical or physical pretreatment is usually required prior to the enzymatic hydrolysis step to disrupt the lignin-hemicellulose matrix and increase cellulose accessibility, which subsequently increases the following hydrolysis efficiency [2].

Over the past decades, different pretreatment technologies have been developed to reduce biomass recalcitrance [3]. Among all the available pretreatment technologies up-to-date, dilute acid-based pretreatment using a variety of acids including sulfuric acid, nitric acid, or hydrochloric acid remains as one of the most important technologies for cellulosic ethanol. It is normally performed with acid concentration less than $4 \mathrm{wt} \%$ over a wide range of temperature $\left(120\right.$ to $\left.210{ }^{\circ} \mathrm{C}\right)$ [4]. It also has been applied on a wide range of feedstock such as poplar [5], switch grass [6], wheat straw [7], rice straw [8], bagasse [9], maize stems [10], and corn stover [11]. It is well known that this acidic type of pretreatment, in the absence of an organic solvent, is less effective in terms of lignin removal, and in fact, the relative content of Klason lignin is normally found to be increased after dilute acid pretreatment. For example, Foston et al. reported that the Klason lignin content significantly increased from $\sim 25 \%$ to $\sim 40 \%$ after dilute acid pretreatment of Populus [6]. This is of course partially due to the loss of carbohydrates especially the hemicellulose during pretreatment. However, Sannigrahi et al. reported that the formation of pseudo-lignin by the dehydration and polymerization of carbohydrates should be responsible for this unusual increase of lignin content [12]. In addition, it was also reported by Li et al. that only $\sim 50 \%$ of the Klason lignin extracted from a hot water pretreated aspen was actual lignin [13]. 


\section{Recent Advances in Petrochemical Science}

Understanding the fundamentals of pseudo-lignin chemistry is important from the bioconversion process perspective. Optimization of current pretreatment technologies is often guided b carbohydrate loss during pretreatment and lignin residue content and/or structure after pretreatment. Lignin is well known to effect enzymatic hydrolysis negatively due to its physical barrier role and its unproductively binding to enzymes $[14,15]$. Therefore, development of novel low pH pretreatments with diminished pseudo-lignin formation will significantly reduce the enzyme loadings required for an efficient enzymatic hydrolysis, hence improve the overall process economics. In conclusion, the formation of pseudo-lignin during any low $\mathrm{pH}$ pretreatment is unfavorable as it originates from carbohydrate degradation and more importantly, it may be even more detrimental to enzymatic hydrolysis compared to native lignin. This mini-review highlights recent advances in understanding the fundamentals of pseudo-lignin formation, the impact of its formation on enzymatic hydrolysis rate and yield, and how to suppress its formation during pretreatment.

\section{Structural Characterization of Pseudo-Lignin}

Table 1: Pseudo-lignin yield during hydrothermal and dilute acid pretreatment of cellulosic substrates [18-20].

\begin{tabular}{|c|c|c|c|}
\hline Sample & Pretreatment conditions & Klason lignin content (\%) & Pseudo-lignin Yield (\%) \\
\hline Avicel cellulose & $140{ }^{\circ} \mathrm{C}, 1 \mathrm{wt} \% \mathrm{H}_{2} \mathrm{SO}_{4}, 30 \mathrm{~min}$ & $\mathrm{~N} / \mathrm{A}$ & 0 \\
\hline Avicel cellulose & $160^{\circ} \mathrm{C}, 1 \mathrm{wt} \% \mathrm{H}_{2} \mathrm{SO}_{4}, 40 \mathrm{~min}$ & $\mathrm{~N} / \mathrm{A}$ & 0.51 \\
\hline Avicel cellulose & $180{ }^{\circ} \mathrm{C}, 2 \mathrm{wt} \% \mathrm{H}_{2} \mathrm{SO}_{4}, 40 \mathrm{~min}$ & $\mathrm{~N} / \mathrm{A}$ & 0 \\
\hline Poplar a-cellulose & $170^{\circ} \mathrm{C}, 0.10 \mathrm{M} \mathrm{H}_{2} \mathrm{SO}_{4}, 20 \mathrm{~min}$ & 6.61 & 44.58 \\
\hline Poplar a-cellulose & $180^{\circ} \mathrm{C}, 0.10 \mathrm{M} \mathrm{H}_{2} \mathrm{SO}_{4}, 40 \mathrm{~min}$ & 37.95 & 51.3 \\
\hline Poplar holocellulose & $180^{\circ} \mathrm{C}, 0.10 \mathrm{M} \mathrm{H}_{2} \mathrm{SO}_{4}, 40 \mathrm{~min}$ & 86.93 & 33.71 \\
\hline Poplar holocellulose & $180^{\circ} \mathrm{C}, 0.20 \mathrm{M} \mathrm{H}_{2} \mathrm{SO}_{4}, 60 \mathrm{~min}$ & 1.5 & Trace \\
\hline Bamboo holocellulose & $170{ }^{\circ} \mathrm{C}, \mathrm{H}_{2} \mathrm{O}, 30 \mathrm{~min}$ & 2 & Trace \\
\hline Bamboo holocellulose & $170{ }^{\circ} \mathrm{C}, \mathrm{H}_{2} \mathrm{O}, 90 \mathrm{~min}$ & 3.1 & 58.2 \\
\hline Bamboo holocellulose & $170{ }^{\circ} \mathrm{C}, \mathrm{H}_{2} \mathrm{O}, 150 \mathrm{~min}$ & 6.2 & 54.1 \\
\hline Bamboo holocellulose & $170{ }^{\circ} \mathrm{C}, \mathrm{H}_{2} \mathrm{O}, 240 \mathrm{~min}$ & & \\
\hline
\end{tabular}

For characterization purposes, pseudo-lignin is normally produced and isolated from dilute acid pretreated lignin-free materials such as $\alpha$-cellulose and holocellulose. Table 1 shows some typical yields of pseudo-lignin isolated from different resources under different pretreatment conditions. A variety of analytical techniques including GPC, FTIR, NMR, SEM have been utilized to characterize pseudo-lignin. Molecular weight (MW) of isolated pseudo-lignin from different resources is shown in Table 2. In general, the MW of pseudo-lignin is much lower than that of milled wood lignin. For example, the weight average MW (Mw) of milled poplar lignin and pseudo-lignin derived from dilute acid pretreated poplar holocellulose at $180{ }^{\circ} \mathrm{C}$ were found to be $10002 \mathrm{~g} / \mathrm{mol}$ and $5050 \mathrm{~g} / \mathrm{mol}$, respectively $[16,17]$. Pretreatment severity was not found to be a huge impact factor on the MW of pseudo-lignin (Table 2) [18-20]. In addition, MW of pseudolignin derived from dilute acid pretreated holocellulose was found larger than that of pseudo-lignin extracted from pretreated $\alpha$-cellulose (Table 2) [16]. FTIR and ${ }^{13} \mathrm{C}$ NMR analysis were also used to provide additional information on the chemical structure of pseudo-lignin, which indicated that pseudo-lignin was mainly composed of hydroxyl, carbonyl and aromatic structures [12]. These results clearly indicated that pseudo-lignin was a polyphenolic, lignin-like material with aliphatic, aromatic, and carbonyl structures derived from cellulose/hemicellulose fragments released during acid hydrolysis reactions.

Table 2: Weight-average $\left(M_{w}\right)$ and number-average $\left(M_{n}\right)$ of pseudo-lignin isolated from dilute acid pretreated cellulosic substrates [18,19].

\begin{tabular}{|c|c|c|c|}
\hline Sample & Mw (g/mol) & Mn (g/mol) & PDI \\
\hline $\begin{array}{c}\text { Bamboo holocellulose pretreated } \\
\text { at } 170^{\circ} \mathrm{C}, \mathrm{H} 2 \mathrm{O}, 150 \mathrm{~min}\end{array}$ & 3410 & 1200 & 2.84 \\
\hline $\begin{array}{c}\text { Bamboo holocellulose pretreated } \\
\text { at } 170^{\circ} \mathrm{C}, \mathrm{H} 2 \mathrm{O}, 240 \mathrm{~min}\end{array}$ & 5340 & 3320 & 1.6 \\
\hline $\begin{array}{c}\text { Poplar a-cellulose pretreated at } \\
180^{\circ} \mathrm{C}, 0.10 \mathrm{M} \text { H2S04, } 40 \mathrm{~min}\end{array}$ & 3440 & 1080 & 3.17 \\
\hline $\begin{array}{c}\text { Poplar holocellulose pretreated at } \\
180^{\circ} \mathrm{C}, 0.10 \text { M H2SO4, } 40 \mathrm{~min}\end{array}$ & 5080 & 1240 & 4.09 \\
\hline $\begin{array}{c}\text { Poplar holocellulose pretreated at } \\
180^{\circ} \mathrm{C}, 0.20 \mathrm{M} \mathrm{H} \text { HSO4, } 60 \mathrm{~min}\end{array}$ & 5970 & 1190 & 5 \\
\hline
\end{tabular}


Lignin can be redistributed during dilute acid pretreatment, leading to the formation of lignin droplets of various morphologies [10,21-24]. During the dilute acid pretreatment, lignin was reported to coalesce on plant cell wall and then migrate into the bulk liquid phase in form of droplets or balls [21]. This kind of lignin aggregation normally requires the pretreatment temperature to exceed the lignin phase transition temperature. Similar to this kind of re-deposit lignin droplets, pseudo-lignin can be also exist as discrete spherical droplets on the surface of pretreated holocellulose with a range of sizes from 0.3 to $8.0 \mu \mathrm{mm}$ [12]. Figure 1 illustrates a SEM image of pseudolignin deposition on surface of poplar holocellulose during dilute acid pretreatment.

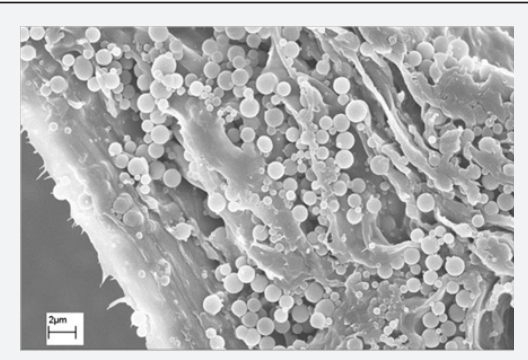

Figure 1: SEM image of pseudo-lignin deposition on surface of poplar holocellulose after dilute acid pretreatment [23].

Reaction Mechanisms Leading to the Formation of Pseudo-Lignin

The exact mechanisms leading to the formation of pseudolignin are still under investigation due to the complexity of pseudo-lignin structure and the heterogeneity of reaction sources and media. However, the presence of high proportions of unsaturated carbons in pseudo-lignin structure strongly indicated that acid hydrolysis of carbohydrates polymers to their corresponding monosaccharide's and the subsequent dehydration and fragmentation of sugars probably took place during the acid pretreatment. Hydroxymethylfurfural (HMF) and furfural can be produced from 6 and 5-carbon sugars such as glucose and xylems via acid catalyzed dehydration reactions $[25,26]$. HMF and furfural can be further subjected to rearrangements to produce other aromatic compounds which might be the key intermediates for pseudo-lignin formation. For example, 3,8-dihydroxyl-2-methylchromone was reported as one of the main aromatic products in the acidic degradation of xylems [27]. Similarly, hydrolytic ring-opening reaction of HMF was reported to generate 1,2,4-benzenetriol (BT0) in yields of $46 \%$ [28]. These intermediates can be then converted to pseudolignin via polymerization/polycondensation reactions. For instance, it has been reported that BTO could react with HMF or furfural to produce a three-dimensional polymer via acid catalyzed aromatic electrophonic substitution [18]. Figure 2 summarized the reaction mechanisms mentioned above, which highly suggested presence of acid and high temperatures are probably two crucial conditions for the pseudo-lignin formation. Understanding the reaction pathways leading to the formation of pseudo-lignin will provide insights into how to suppress pseudolignin generation, though much work still needed to be done.

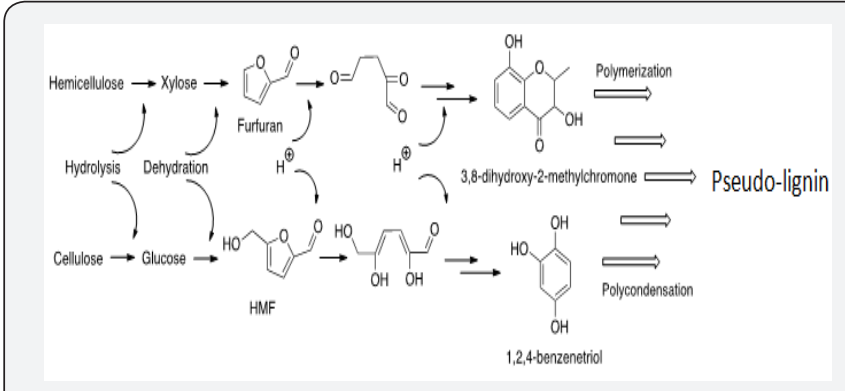

Figure 2: Proposed reaction pathways for pseudo-lignin formation.

Impact of Pseudo-Lignin on Enzymatic Hydrolysis

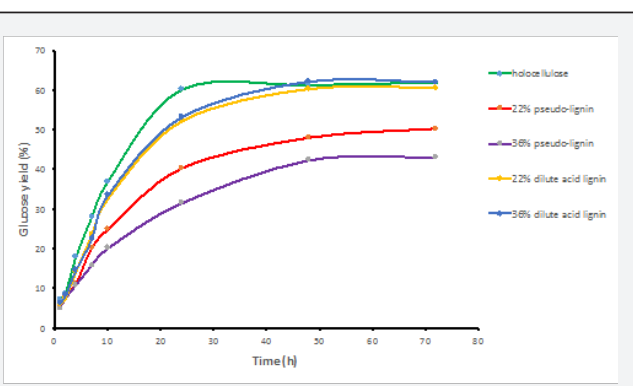

Figure 3: Enzymatic hydrolysis time course of poplar holocellulose mixed with dilute acid pretreated lignin or pseudolignin [30].

$\mathrm{Li}$ and co-workers reported that the lignin droplets deposited on the surface of plant cell wall significantly inhibited cellulose hydrolysis, mainly through surface blockage [21]. Their study indicated the nonspecific binding of lignin droplets to enzymes was not the key source of inhibition. Similar to the lignin redeposit droplets, pseudo-lignin formed during dilute acid pretreatment can also exist as discrete spherical droplets on the surface of pretreated materials, and its formation is obviously not desired due to the fact that pseudo-lignin can directly decrease cellulose accessibility by blocking the surface binding sites. On the other hand, pseudo-lignin is also known to unproductively bind to cellulase and inhibit its action [29]. Kumar et al. studied the enzymatic hydrolysis of Avicel cellulose mixed with pseudo-lignin derived from pure xylose, and it was reported that even a small amount of pseudo-lignin addition could have a noticeable negative impact on enzymatic hydrolysis yield [20]. Further protein adsorption experiments revealed that pseudo-lignin bound to enzymes unproductively. A recent study by Hu et al. further demonstrated the formation of pseudolignin needed to be avoided as they proved that pseudo-lignin is much more detrimental to enzymatic hydrolysis than regular dilute acid pretreated lignin (Figure 3)[30]. More specifically, dilute acid pretreated lignin only inhibited enzymatic hydrolysis in its initial stage and had a nearly negligible impact on the overall conversion percentage after $48 \mathrm{~h}$ as shown in Figure 3 , whereas pseudo-lignin addition could decrease enzymatic 
hydrolysis yield up to $25 \%$ [30]. It is worth mentioning pseudolignin is insoluble in water, therefore the hydrophobic structural functionality of pseudo-lignin is probably responsible for its nonproductive association with enzymes.

\section{Suppression of Pseudo-Lignin Formation during Dilute Acid Pretreatment}

Lignin redeposits droplets and pseudo-lignin only can be formed at elevated temperatures, therefore reducing the pretreatment severity is obviously one of the ways to reduce or avoid the formation of pseudo-lignin. However, as the pretreatment severity decreases, so do the efficient of pretreatment in terms of hemicellulose removal and cellulose accessibility increase. Compared to the typical batch pretreatment, flow through reactor system was shown to dramatically increase lignin removal as much as over 90\% [31]. More importantly, its ability to constantly remove lignin into the aqueous phase effectively restricts the condensation reactions. As a result, flow through pretreatment can reduce the chances of pseudo-lignin formation [31,32].Oxidative polymerization seems to play an important role in pseudo-lignin formation based on the proposed pathway, therefore performing dilute acid pretreatment under non-oxygen environment could be another possible alternative method. It was also reported that introduction of dimethyl sulfoxide (DMSO) to the acidic medium could effectively suppress HMF productions which is one of key intermediates during the pseudo-lignin formation [33]. A recent study modified a series of dilute acid pretreatment by using $\mathrm{N}_{2}$ surfactant Tween-80, or DMSO-water mixture as the reaction medium to test these hypotheses for new methods of suppressing pseudo-lignin formation without significantly reducing the pretreatment severity [34]. As shown in Table 3, addition of $\mathrm{N}_{2}$ was not effective in terms of pseudo-lignin suppression although extra oxygen significantly facilitated pseudo-lignin formation as expected. Apparently, introduction of DMSO significantly reduced the pseudo-lignin content by $\sim 30 \%$. The coordination of HMF with water can be reduced in the presence of DMSO due to the stronger interaction of DMSO oxygen with water [35]. From the reaction mechanism perspective, the reduction of HMFwater coordination could protect the HMF molecule from further reactions to form pseudo-lignin [34].

Table 3: Klason lignin/Pseudo-lignin contents of various samples generated using modified dilute acid pretreatment of poplar holocellulose at $180^{\circ} \mathrm{C}, 1.0 \mathrm{wt} \% \mathrm{H}_{2} \mathrm{SO}_{4}, 40 \mathrm{~min}[34]$.

\begin{tabular}{|c|c|c|}
\hline Sample & Solids recovery (\%) & $\begin{array}{c}\text { Klason/pseudo- } \\
\text { lignin content (\%) }\end{array}$ \\
\hline Control sample & 18.9 & 42 \\
\hline O2 - pretreated & 18.1 & 89.2 \\
\hline N2 - pretreated & 19.1 & 48.7 \\
\hline Tween - pretreated & 37.8 & 14.7 \\
\hline DMSO - pretreated & 13.3 & 52.1 \\
\hline
\end{tabular}

\section{Conclusion}

Lignin-like materials originated from acid catalyzed dehydration of carbohydrate, termed pseudo-lignin, are responsible for the increased Klason lignin content after acidbased biomass pretreatment. Pseudo-lignin can be deposit on the surface of biomass during the dilute acid pretreatment in forms of discrete spherical droplets or balls, and it is detrimental to the subsequent enzymatic hydrolysis, even more detrimental than dilute acid pretreated lignin. Therefore, it became essential to develop techniques to effectively impeded pseudo-lignin formation. Current ongoing pseudo-lignin researches are still quite limited to carbohydrate-derived pseudo-lignins, it is quite possible that lignin would somehow react with carbohydrate degradation products vis polycondensation reactions, contributing to the yield of pseudo-lignin. The understanding of the most fundamental chemistry associated with pseudolignin formation is crucial for the future bioethanol production. Therefore, future work is much needed to fully unlock the secret of pseudo-lignin chemistry.

\section{Acknowledgement}

This manuscript has been authored by UT-Battle, LLC under contract no. DE-AC05-000R22725 with the U.S. Department of Energy. The publisher, by accepting the article for publication, acknowledges that the United States Government retains a nonexclusive, paid-up, irrevocable, worldwide license to publish or reproduce the published form of this manuscript, or allow others to do so, for United States Government purposes. The Department of Energy will provide public access to these results of federally sponsored research in according with the DOE Public Access Plan (http://energy.gov/downloads/doe-public-accessplan).This study was supported and performed as part of the BioEnergy Science Center (BESC). The BESC is a U.S. Department of Energy BioEnergy Research Center supported by the Office of Biological and Environmental Research in the DOE Office of Science.

\section{References}

1. Ragauskas AJ, Williams CK, Davison BH, Britovsek G, Cairney J, et al. (2006) The Path Forward for Biofuels and Biomaterials. Science 311(5760): 484-489.

2. Meng X, Ragauskas AJ (2014) Recent advances in understanding the role of cellulose accessibility in enzymatic hydrolysis of lignocelluloses substrates. Curr Opin Biotechnol 27: 150-158.

3. Hu F, Ragauskas A (2012) Pretreatment and Lignocellulosic Chemistry BioEnergy Research 5(4): 1043-1066.

4. Kumar R, Mago G, Balan V, Wyman CE (2009) Physical and chemical characterizations of corn stover and poplar solids resulting from leading pretreatment technologies. Bioresour Technol 100(17): 39483962.

5. Sun Q, Pu Y, Meng X, Wells T, Ragauskas AJ, et al. (2015) Structural Transformation of Isolated Poplar and Switch grass Lignins during Dilute Acid Treatment. ACS Sustainable Chemistry \& Engineering 3(9): 2203-2210. 
6. Foston M, Ragauskas AJ (2010) Changes in lignocelluloses supramolecular and ultra structure during dilute acid pretreatment of Populus and switch grass. Biomass and Bio Energy 34:1885-1895.

7. Qi B, Chen X, Wan Y (2010) Pretreatment of wheat straw by nonionic surfactant-assisted dilute acid for enhancing enzymatic hydrolysis and ethanol production. Bioresour Technol 101(13): 4875-4885.

8. Hsu TC, Guo GL, Chen WH, Hwang WS (2010) Effect of dilute acid pretreatment of rice straw on structural properties and enzymatic hydrolysis. Bioresource Technol 101(13): 4907-4913.

9. Chen WH, Tu YJ, Sheen HK (2010) Impact of dilute acid pretreatment on the structure of bagasse for bioethanol production. Int J Energy Res 34(3): 265-274.

10. Selig MJ, Viamajala S, Decker SR, Tucker MP, Himmel ME, et al. (2007) Deposition of lignin droplets produced during dilute acid pretreatment of maize stems retards enzymatic hydrolysis of cellulose. Biotechnol Prog 23(6): 1333-1339.

11. Ishizawa CI, Davis MF, Schell DF, Johnson DK (2007) Porosity and its effect on the digestibility of dilute sulfuric acid pretreated corn stover J Agric Food Chem 55(7): 2575-2581.

12. Sannigrahi P, Kim DH, Jung S, Ragauskas AJ (2011) Pseudo-lignin and pretreatment chemistry. Energy Environ Sci 4: 1306-1310.

13. Li JB, Henriksson G, Gellerstedt G (2007) ignin depolymerization/ repolymerization and its critical role for delignification of aspen wood by steam explosion. Bioresour Technol 98(16): 3061-3068.

14. Meng X, Wells T, Sun Q, Huang F, Ragauskas A, et al. (2015) Insights into the effect of dilute acid, hot water or alkaline pretreatment on the cellulose accessible surface area and the overall porosity of Populus. Green Chemistry 17: 4239-4246.

15. Pan X (2008) Role of functional groups in lignin inhibition of enzymatic hydrolysis of cellulose to glucose. J Biobased Mater Bio 2(1): 25-32(8).

16. Hu F, Jung S, Ragauskas A (2012) Pseudo-lignin formation and its impact on enzymatic hydrolysis. Bioresour Technol 117: 7-12.

17. Kim JY, Shin EJ, Eom IY, Won K, Kim YH, et al. (2011) Structural features of lignin macromolecules extracted with ionic liquid from poplar wood. Bioresource Technology 102(19): 9020-9025.

18. Hu F, Jung S, Ragauskas A (2012) Pseudo-lignin formation and its impact on enzymatic hydrolysis. Bioresource Technology 117: 7-12.

19. Ma X, Yang X, Zheng X, Chen L, Huang L, et al. (2015) Toward a further understanding of hydrothermally pretreated holocellulose and isolated pseudo lignin. Cellulose 22: 1687-1696.

20. Kumar R, Hu F, Sannigrahi P, Jung S, Ragauskas AJ, et al. (2013) Carbohydrate derived-pseudo-lignin can retard cellulose biological conversion. Biotechnol Bioeng 110(3): 737-753.

21. Li H, Pu Y, Kumar R, Ragauskas AJ, Wyman CE, et al. (2014) Investigation of lignin deposition on cellulose during hydrothermal pretreatment, its effect on cellulose hydrolysis, and underlying mechanisms. Biotechnol Bioeng 111(3): 485-492.

This work is licensed under Creative Commons Attribution 4.0 Licens
22. Zhang H, Wang YJ, Lü F, Chai LN, Shao LM, et al. (2015) Effects of Dilute Acid Pretreatment on Physicochemical Characteristics and Consolidated Bioprocessing of Rice Straw. Waste and Biomass Valorization 6(2): 217-223.

23. Pu Y, Hu F, Huang F, Davison BH, Ragauskas AJ, et al. (2013) Assessing the molecular structure basis for biomass recalcitrance during dilute acid and hydrothermal pretreatments. Biotechnology for Biofuels 6(1): $1-13$.

24. Zeng Y, Zhao S, Wei H, Tucker MP, Himmel ME, et al. (2015) In situ microspectroscopic investigation of lignin in poplar cell walls pretreated by maleic acid. Biotechnology for Biofuels 8: 126.

25. Kim ES, Liu S, Abu-Omar MM, Mosier NS (2012) Selective conversion of biomass hemicellulose to furfural using maleic acid with microwave heating. Energy Fuels 26(2): 1298-1304.

26. Li J, Henriksson G, Gellerstedt G (2005) Carbohydrate reactions during high-temperature steam treatment of aspen wood. Appl Biochem Biotechno 125(3): 175-178.

27. Popoff T, Theander $O$ (1972) Formation of Aromatic Compounds from Carbohydrates. Carbohydrate Research 22: 135-149.

28. Luijkx GCA, Van RF, Van BH (1993) Hydrothermal formation of 1,2,4-benzenetriol from 5-hydroxymethyl-2-furaldehyde and d-fructose. Carbohydrate Research 242: 131-139.

29. Vivekanand V, Olsen EF, Eijsink VGH, Horn SJ (2013) Effect of different steam explosion conditions on methane potential and enzymatic saccharification of birch. Bioresour Technol 127: 343-349.

30. Hu F, Jung S, Ragauskas A (2013) Impact of Pseudolignin versus Dilute Acid-Pretreated Lignin on Enzymatic Hydrolysis of Cellulose. ACS Sustainable Chemistry \& Engineering 1(1): 62-65.

31. Yan L, Zhang L, Yang B (2014) Enhancement of total sugar and lignin yields through dissolution of poplar wood by hot water and dilute acid flow through pretreatment. Biotechnology for Biofuels 7: 76.

32. Shen H, Poovaiah CR, Ziebell A, Tschaplinski TJ, Pattathil S, et al. (2013) Enhanced characteristics of genetically modified switchgrass (Panicum virgatum L.) for high biofuel production. Biotechnology for Biofuels 6: 71.

33. Román Leshkov Y, Chheda JN, Dumesic JA (2006) Phase Modifiers Promote Efficient Production of Hydroxymethylfurfural from Fructose. Science 312(5782): 1933-1937.

34. Hu F, Ragauskas A (2014) Suppression of pseudo-lignin formation under dilute acid pretreatment conditions. RSC Advances 4: 43174323 .

35. Mushrif SH, Caratzoulas S, Vlachos DG (2012) Understanding solvent effects in the selective conversion of fructose to 5-hydroxymethylfurfural: a molecular dynamics investigation. Phys Chem Chem Phys 14(8): 2637-2644.

\begin{tabular}{l} 
Your next submission with Juniper Publishers \\
will reach you the below assets \\
- Quality Editorial service \\
- Swift Peer Review \\
- Reprints availability \\
- E-prints Service \\
- Manuscript Podcast for convenient understanding \\
- Global attainment for your research \\
- Manuscript accessibility in different formats \\
( Pdf, E-pub, Full Text, Audio) \\
- Unceasing customer service \\
Track the below URL for one-step submission \\
https://juniperpublishers.com/online-submission.php \\
\hline
\end{tabular}

